\title{
Assistant Principals' Perceptions Regarding the Role and the Effectiveness of an Educational Leadership Program
}

\author{
Gary B. Peters ${ }^{1}$, D. Keith Gurley ${ }^{1}$, Matthew Fifolt ${ }^{2}$, Loucrecia Collins ${ }^{1} \&$ Rose McNeese $^{1}$ \\ ${ }^{1}$ Department of Human Studies, University of Alabama at Birmingham, USA \\ 2 Evaluation and Assessment Unit, Center for the Study of Community Health, University of Alabama at \\ Birmingham, USA \\ Correspondence: Gary B. Peters, Department of Human Studies, University of Alabama at Birmingham, USA
}

Received: November 29, 2015

Accepted: December 18, $2015 \quad$ Online Published: December 22, 2015

doi:10.5430/ijhe.v5n1p183

URL: http://dx.doi.org/10.5430/ijhe.v5n1p183

\begin{abstract}
In this study, faculty members of an educational leadership program, situated in a large urban university in the southeastern region of the United States, utilized focus group research to determine the perceptions of K-12 assistant principals regarding the effectiveness of an educational leadership program, and to provide recommendations for program leaders for program improvement to increase job preparedness for emerging school leaders. This qualitative study included collecting, transcribing, and analyzing data from two focus group interviews. The nine study participants had all graduated from an educational leadership program at the focus institution and were actively serving as assistant principals in the university service area. Researchers determined common themes and patterns from the data. Findings indicated that, while respondents felt generally well prepared by their university leadership program, they also identified challenges faced by assistant principals today as complex and consequential in nature. Respondents spoke of responsibilities beyond the realm of traditional program preparation that required the acquisition of skills learned through real life applications. The formal acquisition of knowledge that was theoretical, practical, and methodological was not minimized, but rather placed in cultural context, providing insight and implications for the leadership preparation program improvement.
\end{abstract}

Keywords: Assistant principals, Leadership, School leadership roles, Leadership program evaluation

\section{Introduction}

\subsection{Introduction of the Problem}

\subsubsection{Introduction}

The consistent and systematic examination and reflection upon any program in higher education is of value to program faculty, institutions, and certainly to students. Faculty reflection upon the quality of program design and implementation efforts to evaluate program effectiveness is meaningful to the process of educational reform and improvement (Backor \& Gordon, 2015; Yirci \& Kocabas, 2010).

Educational leadership programs, offered by institutions of higher education across the nation, are no exception. Such systematic evaluation may provide information necessary to examine how well an educational leadership program or initiative is being implemented, and may help faculty members determine whether that program is achieving desired results and where changes in curriculum or instructional delivery may be indicated.

In this article, we describe findings from a reflective activity our research team conducted involving focus group discussions with nine recent graduates from our educational leadership program, each of whom was serving as an assistant principal in K-12 public schools within the university service area. The primary goal of this activity was to inform leadership program faculty members regarding the perceived effectiveness of the program to meet the needs of our students to assume the often demanding role of the assistant principal (AP).

We begin by providing some background, first from the relevant literature regarding educational leadership program effectiveness, and then on the empirical literature exploring the role of the AP, in general. After presenting the findings from our study, we reflect on the expressed perceptions of our respondents, informed by the adopted conceptual frameworks of occupational and professional socialization. We conclude the article by presenting team reflections regarding what we learned about the effectiveness of the specific leadership preparation program under 
study, and how we as a program faculty might proactively seek to more effectively prepare our school leadership students to enact the role of AP in the schools they serve.

\subsection{Review of Literature}

The effective leadership of administrators within their school organizations directly impacts classroom improvement (Fullan, 2003; Halverson \& Plecki, 2015; Sergiovanni, 2001). The multi-faceted roles that today's assistant principals (APs) assume are complex and ever-evolving. Educators who are just beginning their administrative careers are often thrust into responsibilities that tax their professional training in a formal environment. The traditional programs by which universities prepare educational leaders have increasingly become a matter of open discussion (Backor \& Gordon, 2015; Lashway, 2003), and this has led to an introspective examination of program preparation.

\subsubsection{Educational Leadership Program Effectiveness}

A disconcerting critique of university preparation programs for educational leaders has increasingly garnered support within academia (Hess \& Kelly, 2005; Levine, 2005). The national attention received by scholars questioning program effectiveness has led to a renewed focus on educational leadership preparation by the universities themselves (Orr \& Pounder, 2006). Today, there is a perpetual examination of educational leadership program design and implementation efforts (Backor \& Gordon, 2015). Effective leadership preparation is essential to meaningful educational reform and improved student achievement (Yirci \& Kocabas, 2010). Evaluation provides the information necessary to examine how well a program or initiative is being implemented and to determine whether that program is achieving desired results. A brief review of the conversation among educational leadership scholars is helpful.

Donmoyer, Imber, and Scheurich (1995) observed that beginning in the 1980s, there was an increasing interest in developing a better understanding and appreciation of administrative preparation for school leaders. Foster and Ward (1998) identified reform efforts of the 1990s as a catalyst for greater scrutiny and advancement of administrative preparation programs. "From their early role as the principal-teacher to the school manager in the later part of the $20^{\text {th }}$ century, today's principal is being asked to assume the $21^{\text {st }}$ century role as the school catalyst for all stakeholders" (Wilmore, 2002, p. 5).

Lehman (2013) added, 'Overall, the term 'hands-on' was by far the most frequently used term to describe how to improve the experiences of administrative interns" (p. 11). Institutions today operate in a societal structure constantly adapting to technology and new forms of communication (Kotter, 1985).

Leithwood and Duke (1999) wrote that while much has been learned about leadership, "it has not depended on any clearly agreed upon definition of the concept, as essential as that would seem at first glance" (p. 45). The challenges of school administration are simply too complex for administrators to work alone without the assistance of others in the school community (Blase, J., \& Blase, J. J., 2006). Hallinger and Heck (1998) observed "relationships between the administrator and features of the school and its environment are interactive" (p. 168). Bolman and Deal (1997) identified leadership as an integral part of organizational success, and the advancement of any organization is proportionate to the adapted practices of the leader. Leadership and school culture are often caught in changing identities and values. "Within this, however, there may exist several cultures: pupil culture, teacher cultures, a leadership culture, non-teaching staff culture, and parent culture" (Stoll, 1998, p. 10).

In light of these implications, educational leadership faculty members across the United States have demonstrated a commitment to continuous improvement of school leadership preparation programs. Young, Mountford, and Crow (2005) stated, "Across the nation, many faculty members have been working to improve leadership preparation for years. Their efforts range from realigning programs to address national leadership standards to drastically reforming and restructuring ineffective programs" (p. 3). Examples of such reforms include structuring educational leadership programs to include greater levels of collaboration between students, and between institutions of higher education and schools and school districts, intensive coaching and mentoring of emergent school leaders, and increased levels of field-based experiences for leadership candidates (Cosner, Tozer, \& Smylie, 2012; Isreal \& Fine, 2012)

\subsubsection{Research on the Assistant Principalship}

The position of assistant principal (AP) was originally introduced into schools in the United States in the 1930s, designed primarily as a support person to reduce principal workloads (Glanz, 1994; Harvey, 1994). Initiating the empirical dialogue on APs, Austin and Brown (1970) described roles and responsibilities of the AP, declaring them essential to overall school effectiveness, while also acknowledging that APs are typically relegated to variety of often menial, unrelated tasks.

Austin and Brown (1970) first posed the question as to whether or not the AP role would be a suitable one to prepare 
school leaders to assume the role of instructional leader of a school. More recently, other researchers have joined the conversation by identifying long lists of managerial duties typically assigned to APs (Glanz, 1994; Harvey, 1994; Webb \& Vulliamy, 1995). Glanz (1994) reported that APs often reported low levels of job satisfaction due to a mismatch between what these leaders identified as important functions of school leaders and their own daily work.

Call for Change. Researchers generally agreed regarding relegation of the AP to primarily managerial functions. Many joined in a call to begin to re-conceptualize the role (Fulton, 1987; Greenfield, 1985; Harvey, 1994; Marshall \& Greenfield, 1987; Miskel \& Cosgrove, 1985; Pellicer, Anderson, Keefe, Kelly, \& McCleary, 1988). These experts decried the perceived wasted potential of APs, proposing that, by refocusing the role on developing instructional leadership among APs, greater resources might be brought to bear on improving teaching and learning in schools (Hartzell, 1993; Hartzell, Williams, \& Nelson, 1995; Marshall, 1992; Marshall \& Mitchell, 1991).

Continuing the Dialogue. Over the last decade, researchers have continued to examine the assistant principalship. Marshall and Hooley (2006) recommended that those who determine job descriptions for, and supervise, APs consider more broadly defining the role, and therefore the potential for more effective on-the-job training, for these leaders. Martinez (2011), of the University of Houston, concurred, calling for the "transformation of the role of the assistant principal from the present reactive, managerial approach [to a more] proactive approach that is needed in the $21^{\text {st }}$ century" (para. 1).

Of particular interest to the current study, Armstrong $(2004,2009)$ contributed insight into the transition and the process of role conceptualization that APs experienced upon entry into this formal school leadership position. Armstrong interviewed eight newly-appointed vice-principals (APs) in Canada, shining light on their experiences relative to their administrative careers. Armstrong has made important contributions to the conversation regarding this important phase of professional redefinition for vice-principals (APs).

Barnett, Shoho, and Oleszewski (2012) examined the job realities of the position in a qualitative study of over 100 APs in south Texas. These researchers reported that the role of the AP is characterized by "excessive workload demands" (p. 104). Respondents described the challenges of balancing workload expectations and reported that managing student discipline and attendance issues comprised vast amounts of their daily work.

Shoho, Barnett, and Tooms (2012) compiled the work of several international researchers exploring the role of the AP (Boske \& Benavente-McEnery, 2012; Busch, MacNeil, \& Baraniuk, 2012; Kwan \& Walker, 2012; Melton, Mallory, Mays, \& Chance, 2012; Read, 2012; Rintoul, 2012). As one example, Busch et al. (2012) gathered the wisdom of acting APs who pointed out the critical need for upcoming school leaders to more fully understand the demanding nature, difficulty, and complexity of the job.

Despite this decades-long study and dialogue regarding the role of the AP, the complexity of the role does not appear to have decreased. This conclusion served to point the attention of the researchers for the current study to focus on how well our specific university-based, educational leadership program has prepared APs to assume such a demanding and diverse role in schools in our university service area. It is in the hope of contributing to this continued dialogue that we present findings from the current research study.

It is our hope that the findings reported here resulting from our reflective activity with these assistant principals will add to the emerging and important dialogue among educational scholars regarding the role of assistant principals in schools today. Further, our research team hopes to contribute to the body of reflective literature related to program improvement in higher education, and in educational leadership programming, specifically.

\subsection{Conceptual Frame}

To frame the current study (as well as a parallel study we conducted simultaneously [see Gurley, Peters, Fifolt, Collins, \& McNeese, 2015]), our research team adopted a general, conceptual perspective of occupational socialization. Gordon (1998) provided a general definition of occupational socialization as "the learning of attitudes and behaviors necessary to recognized and sustainable competence within a context of employment. These include skills acquired through training, informal work norms, and peer-group values and relationships" (para. 1). Occupational socialization is rooted in the empirical study of developmental and industrial psychology and focuses on the continuous development of individuals within the context of their occupational/workplace settings.

Frese (1982) provided a succinct overview of the empirical literature exploring occupational socialization and points to the following effects of occupational socialization: (a) changes to the worker's actions outside the workplace; (b) effects on worker cognition; (c) effects on worker emotions; and (d) changes in worker values, especially of a worker who has just assumed a new role in the workplace (p. 209). Our team adopted a framework of these four effects to guide our thinking and inform the analysis of findings from this study. Results of the application of this framework 
will be presented in the discussion section of this article.

The research team also gained insights from Miller (2010, 2013) and Shuval (1980) who described a three-stage process of professional socialization composed of: (a) a pre-socialization stage, (b) a formal socialization stage, and (c) post-formal or on-the-job stage that occurs after individuals enter their professional field of practice. While our team did not collect data relative to the pre-socialization processes experienced by study respondents, reflection on the second and third stages of the professional socialization model (i.e., formal and post-formal) also informed our analysis of the findings.

Finally, related to the socialization process experienced by developing school leaders, specifically, our team was also informed by the role conception work of Browne-Ferrigno (2003). Brown-Ferrigno argued that aspiring school leaders experience a professional socialization process that begins early in the teaching career and continues to develop into and beyond matriculation to formal, school leadership positions. Browne-Ferrigno advocated for a deeper understanding, on the part of those engaged in school leadership preparation, of the continuous process in which individuals engage to define and re-define the roles school leaders must play in school-based situations. These multiple, but related conceptual frameworks regarding the occupational and professional socialization of school leaders helped guide our team toward an enhanced understanding of the complexity of roles that assistant principals are expected to enact in contemporary school settings, the effects described by respondents resultant from the assumption of the assistant principalship, as well as our team reflections on what study respondents shared regarding their perceptions about the effectiveness of the school leadership program, from which they graduated, to prepare them for such roles.

\section{Method}

\subsection{Study Purpose}

The overall purpose of this study was to determine respondents' roles as APs and perceptions regarding their preparation to assume leadership roles as APs in Alabama K-12 schools. This study focused on specific program features that were identified by participants, through their own personal experiences in the program, as being strong, contributory, or worthy of mention. The central research question addressed in the study was: Did your educational leadership program prepare you for the roles as an assistant principal? The focus of this question was significant in understanding the challenges that APs experience and the extent to which they have been successfully prepared for their administrative careers.

Focus group methodology is a qualitative research approach that provides an opportunity for accurate and pure data to be captured in a group interaction. Merriam and Associates (2002) stated qualitative research provides an opportunity to understand the participants' views in the context studied. Focus groups "encourage a range of responses which provide a greater understanding of the attitudes, behavior, opinions or perceptions of participants on the research issues" (Hennink, 2007, p. 6). The procedures for data collection and analysis evolved in response to participants' early contributions to the study. This emergent design embraced change as information became available and allowed the researchers to reflect between groups and make design changes.

\subsection{Study Sample}

A purposive sample of participants was selected from among Educational Leadership graduates who (a) completed a master's degree, (b) hold a certificate in Instructional Leadership in Alabama, and (c) are currently serving as APs in K-12 schools in Alabama. Participation in the focus group interviews was strictly voluntary. Questions posed in the group interview setting allowed participants the option of answering. The questions inquired about participant perceptions of their current roles as APs in K-12 schools and of their perceptions of the adequacy of an Educational Leadership program to prepare them for these roles.

\subsection{Data Collection}

Researchers conducted two different focus group interviews with individuals who had graduated from our educational leadership preparation program and who currently serve in a K-12 school as an AP. The first group included six program graduates; the second group included an additional three participants. Each of the focus group sessions was conducted at a time conducive to all participants and lasted approximately 90 minutes. No participant, school, or district was identified in any subsequent reporting of the data.

All four faculty members from the educational leadership preparation program participated in facilitating the focus group sessions, alternating the task of posing questions to respondents. Three of the four faculty members were known to respondents, while the fourth had recently joined the program faculty, and was therefore less familiar to 
focus group participants. Specific questions/prompts posed by faculty members included the following:

1. Talk about the roles you have played in your position as an assistant principal.

2. In what roles, if any, do you feel unprepared or unqualified to perform as an AP?

3. Complete this statement: Leadership preparation programs for assistant principals should address...

4. How well did your educational leadership program prepare you for the roles as an assistant principal? Explain.

5. Is there anything else you would like to share regarding your experience as an AP and/or your educational leadership preparation program?

These focus group interviews provided an opportunity for participants to voice their thoughts and feelings openly (Creswell, 2003). Responses from focus group participants were recorded by hand and audio device, then transcribed, and analyzed for content to determine respondent roles as APs and perceptions regarding their preparation to assume leadership roles as APs in Alabama K-12 schools. The qualitative responses were read and analyzed separately, then collaboratively, by researchers to identify patterns. The process of constant comparison saturated the conceptual relationships into the categories and themes described here (Glaser, 1978; 1992). Five themes and 17 sub-themes emerged from this analysis.

For this study, the researchers used three validation strategies. First, the researchers used rich, thick descriptions to share information pertaining to the participants (Creswell, 2007). Second, peer debriefing provided an external check of the research process (Lincoln \& Guba, 1985). And finally, researchers applied triangulation by using multiple and different sources to provide corroboration (Patton, 1990).

\subsection{Limitations to the Study}

The research team acknowledges some key limitations to the study. First, the small number of participants, a convenience sample, was not representative of the entire group of program graduates. The findings, however, while not generalizable beyond this specific group of participants, provide an opportunity for researchers to better understand the thoughts, impressions, and reasoning of the culture of the leadership program in question and the perceptions of participants regarding their experiences in and reflections on the program (McCracken, 1988). Further, because faculty members felt satisfied with the richness of the data immediately following the focus groups, individual follow-up interviews were not conducted. We acknowledge that individual interviews with each participant would have added to the richness of the data corpus and, perhaps, further insight into respondent perceptions.

\section{Results}

Findings from this study coalesced around four themes which emerged from our reflection on and discussion of these data. The first theme suggests that respondents became aware of powerful gaps in knowledge in the context of their work, after the respondents assumed positions as school leaders. Second, an unexpectedly powerful finding suggests that substantial emotional challenges are present for respondents, both personal and professional, in their efforts to address the challenging needs of students. Third, a reminder that real life application of knowledge gained in university coursework to the specific leadership settings is a critical component as respondents discussed the connection between what they learned in class and what they are able apply in their jobs. Finally, the importance of mentoring and of developing professional and personal support systems was emphasized by this group of school leaders. We address each of these themes, and related sub-themes, in the section that follows.

\subsection{Gaps in Knowledge}

The first theme, labeled Gaps in Knowledge, and related sub-themes, are presented in Table 1. The first theme represents gaps participants identified between their knowledge base and the duties they are expected to perform as APs. These gaps were confounded by the fact that these APs were no longer teaching in the classroom on a daily basis. One participant noted, "The longer that I am out of the classroom the more that I have to bridge the gap". These identified gaps included sub-theme areas of professional expertise including technology, program management, and finances that continue to evolve, and therefore, demand new skill sets from our study participants. Struggling with the time required to gain administrative skills in their new leadership positions, while also retaining classroom expertise and best practices, makes for a difficult transition for participants. 
Table 1. Gaps in Knowledge Theme, Sub-themes, and Illustrative Quotes

Gaps: "I have to bridge the gap."

Technology

Program Management

Finances
"As you get further and further away...you didn't do it [technology] or you did it but it was two years ago. You are trying to make sure that you are able to assist them [teachers]. A lot of times I do find myself referring them to somebody else."

"I am the liaison with everyone from the Alabama High School Athletic Association, to the NCAA, to testing, and corporations."

"I am always concerned about the financial animal. Because there is this conversation about training new principals in the financial part of running a school with budget and balancing the books and looking at the bank statement. But they never want to do that with the APs."

\subsubsection{Technology}

Regarding the time required to develop administrative skills in their school settings, participants suggested instructional expertise may be compromised, resulting in gaps of knowledge relative to the implementation of technology for instructional purposes. One participant shared,

And for us [APs], being out of the classroom for a period of time, we kind of missed that part [technology] because in the process of becoming an administrator and enjoying the assistant principal role, a lot of times we miss out on things that are transitioning in the classroom toward $21^{\text {st }}$ century learning.

The mentoring of teachers in the use of technology in instructional practice, which these young administrators acknowledged is critical to teachers' success, was noted by another participant, "I'm not as good of a mentor to [teachers] as things such as technology and programs do change in schools." A third participant concluded, "If you don't really have an understanding [of technology], how can you truly evaluate teachers?"

In reflecting on their coursework during their leadership program, participants recalled one professor's requirement in which they compared and assessed 30 different technology tools during a single course. While the expectation was intensive, participants agreed the course requirement advanced their knowledge and application of new technologies. "I've worked my tail off ... and I feel like it is quality information... I had to do a lot of hard quality work and couldn't just half-way do it, because you [instructors] expected more and I expected more." Participants agreed that they felt prepared in their graduate school training. Despite this training, however, the knowledge gap in technology emerged from their experience after graduation and after they began serving in the role of assistant principals. The challenge to keep technological expertise current was often a daunting task while engaged in on-the-job administrative duties.

\subsubsection{Program Management}

In addition to the concerns regarding gaps in technology skills and expertise, another sub-theme of the study dealt with program management areas to which young administrators had been assigned. APs spoke of their daily management roles, which included oversight and accountability of specifically assigned program areas. These programs required immediate and explicit expertise. An area of concern was the highly accountable nature of athletic program management. The area of program management gave rise to issues involving facility usage, disputes, paperwork, compliance, time constraints, communication, and finances. This program area has grown to occupy more of the administrators' time and resources. The AP is increasingly serving as a liaison to multiple agencies.

A participant shared the challenge of thoroughly knowing the High School Athletic Association Handbook, so as to adhere to the "athletic side of eligibility of the NCAA standards," and to simply have "that type of athletic knowledge." Participants identified athletic program management as an increasingly complex responsibility for both men's and women's sports. Concern about the high stakes associated with NCAA academic standards and rules interpretation, reporting, and accountability were prevalent. A participant made this point when he stated, “...especially high school when you look at the athletic side of eligibility of NCAA standards, buses, or transportation." Further discussion ensued about the emerging role of APs who must forge a strong relationship with school counselors due to overlapping responsibilities in athletic program management. Additionally, the APs' widening scope of responsibilities carries greater accountability and consequences. 


\subsubsection{Finances}

Other participants introduced a third sub-theme when they spoke of the "financial animal", as if a lurking beast were roaming the hallways. Explaining his terminology, the AP elaborated, "There's always this conversation about training new principals in the financial part of running a school with budget and balancing the books and looking at the bank statement...but they never want to do that with the assistant principals." The term "financial animal" was aptly used to describe the unknown nature of this perceived adversary. The key word in this conversation was that of dealing with the "unknown".

Administering a school budget was a concern for these APs. They were anxious to learn, practice, and experience first-hand the financial intricacies of a school organization, but explained that they are often not offered these opportunities by their building administrator. Another participant further illustrated this point,

We don't fool with the money, the only money that I fool with now, and that's only because I am in athletics, is the athletic budget and even then all I am doing is signing purchase orders and moving money around.

This participant indicated that the true fiscal responsibility of school management was not something he experienced in the AP role rather it was simply the mundane tasks of signing papers and reporting. This gap noted by APs was the inherent responsibility of budgetary oversight and management in the principalship for which participants felt ill-prepared.

The identification of the gaps between these APs' knowledge base and the expectations placed upon them in their daily responsibilities was a substantial concern expressed by participants in this study. These gaps seemed to be exacerbated the longer they spent in the AP role and the more removed they felt from the classroom setting over time.

\subsection{Feelings and Emotions on the Job}

A second theme that emerged from our analysis of these focus group conversations addressed the affective domain. Study respondents spoke of the emotional challenges of the job and the feelings they experienced on a daily basis. Respondents described their heartfelt desire to "change the world" when they entered the position and how that desire at times came into direct conflict with the often overwhelming demands of the job. This theme and related sub-themes are presented in Table 2.

An unanticipated finding from the study was participants' expression of their feelings and emotions-their general psyche-as it relates to workplace environment and the interaction between their workplace and their home or personal lives. One participant declared, "This is going to sound a little cynical, but I think that there should be an understanding [by people considering the AP role] that this is not a role that's for the weak of heart." Though sometimes deeply personal, this topic was openly discussed by participants in both focus group sessions.

\subsubsection{AP Roles}

In describing the multiple roles they were assigned as APs, and some significant related factors such as time, resources, and accountability, participants spoke of the "emotional weight," "stress," and "all the negative" aspects of the AP position. The frustration of trying to meet everyone's needs was aptly described by one respondent who stated, "And that's what we are; we're all things to all people." Another continued, "Because if I really could get

Table 2. Feelings and Emotions Theme, Sub-themes, and Illustrative Quotes

Feelings and Emotions: "I wanted to save the world, but I just...wow."

AP Roles

"I feel the assistant [principals] get so many of the negative jobs and you know, we work together well...but it's overwhelming when all the negative is what you see so often and you don't get to see the positive."

Concern for Students

"The emotional weight of sad things that happen to kids or kids who are depressed or kids who are suicidal, or kids that $[s i c]$ have needs that you completely as a teacher never knew that they had."

Coping

"[You have] to find ways to protect yourself emotionally and then to find ways to help the kids emotionally." 
it in my life to completely separate myself from work and home on the way home, I probably would not be a crazy woman". The perspective offered by yet another participant was direct. He stated that at his school there is just "one assistant principal for the high school, so I get all the really crappy stuff."

\subsubsection{Concern for Students}

Concern for students emerged as another sub-theme as APs described how they struggled not only with their own roles but also with the plight of many students they encountered on a daily basis. One AP commented, "I work real closely with our counselor dealing with issues that aren't behavior, but things that kids are dealing with." And, speaking about students' home lives, another AP noted, “... [it's] not just the stress for us, it is stress for the students."

These APs also delved into their own feelings and emotional responses and pressures they felt when making decisions about students in loco parentis, or in sorting out and deciding issues of legal liability, residency, custody battles, conflict resolution, disciplinary decisions, special needs considerations, and often the deplorable home lives of their students. The following statement captures the thoughts of many participants, "And you just, I don't know, my heart just cries out for them [students] and I don't think I was ready for that."

In the everyday activity of school life, APs are often uniquely and intensively exposed to societal ills which strike a deep concern within them. School administration exacts a heavy toll, a toll which affects not only the workplace, but also often their home lives, as well. A participant confided, "But when you get home, you still take a lot of that with you." Responding to a parental incident at school the participant continued,

You get caught up in a little bubble that, oh my God, we are the only people who ever have to deal with a crazy parent who says this. But then you come together and you have all of your people and you find out that number one, they deal with crazy parents, too, and sometimes you leave there and you feel better about yourself.

Reflecting on her interactions with her own students, one AP concluded, "It is the most challenging role I've ever had, and it's also been the most rewarding, which is the reason, I guess, I continue to do it."

\subsubsection{Coping}

A third emergent sub-theme under this theme of Feelings and Emotions was that of coping as participants spoke of attempting to balance the emotional consequence of work with their personal and home lives. Addressing the magnitude of this issue, a participant shared, "And it's just such a bigger [sic] scale of all the sad, sad, things that are happening...the emotion part is a lot." Participants were conflicted, "It's overwhelming when all the negative is what you see so often and you don't get to see the positive." One participant quietly and reflectively uttered a series of questions as if he were reliving previous decisions and situations. He questioned:

When do you call the Department of Human Resources? What do you do if a kid is suicidal? Are there forms to fill out because you need a form before you release a suicidal kid somewhere? You know, like that kind of stuff, to find ways to protect yourself emotionally and then to find ways to help the kids.

One participant noted the difference between the AP role and that of a building principal, stating that, in his educational leadership preparation program, he did not receive training specifically pursuant to the AP role. He explained:

So you're not really getting that type [of instruction], you're getting the things that help you prepare to be a principal, but some of those things on the assistant principal side is [sic] just a different role than you take on, that says, "Look at different things".

With a chuckle, one AP suggested the leadership program faculty consider adding what he termed a "new scenarios class" to the course sequence for pre-service school leaders. Especially when preparing individuals to assume the role of AP, he suggested, "Just hit them [graduate students] up with the craziest things, and that won't even come close to what actually comes through the door on most days."

Related to this sub-theme of coping, our research team also noted what we describe as a sense of "calling" evident in the participant responses. APs dealt with the emotional weight of their job in different ways, but within their collective responses we noted an abiding compassion for students in their schools. One participant's statement captured the sentiment of all when he stated, "I got slammed a little bit. And I'm very personable, very kind, compassionate, caring. I wanted to save the world, you know, but I just...Wow!"

In what seemed like an attempt to put things in perspective, another respondent reflected, "It seems like, for me, the 
assistant principal role is a calling. It is definitely mission work, and you have to take your job seriously and also take yourself lightly on many occasions." Seeming overwhelmed by the onslaught of humanity at times, there remained a genuine sense of altruism emerging from the APs' discussion of their daily administrative roles and responsibilities, despite the heavy emotional demands and personal toll.

\subsection{Real Life Applications}

The third theme that emerged from the data addressed specific program preparation in a cultural, or what participants referred to as a "real life", context. This theme, which we labeled real life applications, and its related sub-themes, are presented in Table 3 along with illustrative quotes.

The prevailing thought among respondents was that formal, educational leadership preparation programs alone simply cannot respond to all societal and situational challenges that will be faced by APs. Illustrative of this theme, one participant noted, "You can never think of enough situations, as our professors, to prepare us".

\subsubsection{School-specific Learning}

Respondents generally felt that it is in the non-formal educational practices that graduate students often gain the most insight and "real life" application skills. "You have to know your principal, you have to know your school's mission, and you have to know the way things are done in your building," stated one AP. Another advised, "Just prepare people for the reality of the fact that it is a multi-faceted job". A third agreed adding, "There are so many different hats that you have to wear, that there is still this disconnect, or something".

When asked if their leadership preparation program adequately prepared them for the position of AP, several participants added a slightly different perspective, suggesting a presence of the element of surprise accompanying the job. One AP stated, "Preparedness...it [leadership] is really real, and it's not what you thought as a teacher". Another confided, "I felt prepared...but you just don't know what's coming". Yet another participant shared, "I don't know how you could be [prepared]".

Table 3. Real Life Applications Theme, Sub-themes, and Illustrative Quotes

\begin{tabular}{l} 
Real Life Applications: "Some things you'll never teach me until I get there. Never." \\
\hline School-Specific \\
that," of the stuff that you do is very school specific, so there's no way for you to teach
\end{tabular}
that."

Practical Learning

"There's a lot of practical stuff that you can't do beforehand like when you like search somebody or you search a car."

The Shock

"It wasn't that I felt unprepared because, I think I was unaware of how different the shock was going to be."

Guest Speakers

"Just to hear their war stories."

Participants further spoke of developing "a working knowledge" of the job that comes only from actually performing the duties on a daily basis. They also spoke of "developing their own style" as school leaders. One AP stated, "...but once you get in there and actually, the rubber meets the road, and you send the kid to alternative school or whatever, it's just a different kind of feel".

Participants also agreed that much of what they had learned about being an AP was necessarily site- or school-specific learning, illustrated by one comment, "I don't think I can ever be prepared for the situation. I mean because it's very school-specific, system-specific." Building on this thought, another participant noted, "A lot of the stuff that you do is very school-specific. And there's no way for you to teach that in a master's, educational specialist, or even doctoral course....So, I felt prepared...you just don't know what's coming". Another participant drew a parallel between leadership preparation and the process of preparing classroom teachers to manage their own classrooms, "You can talk about how to manage a classroom and you can teach them all the classroom management strategies, but until they get in there and they develop their own style, there is a little bit of disconnect". Continuing to emphasize this point, another AP shared, "Those are all things that you jump in and learn to do on the fly-on the job." 


\subsubsection{Practical Learning}

One participant referred to program preparation as "practical stuff", and others further defined the intent, "I think probably a real practical kind of [approach might include] how you do an exit interview". The program from which these respondents graduated requires that students pass an exit interview as part of the program completion requirements at the master's level. In the exit interviews, conducted in partnership between a program faculty member and a practicing school administrator, students practice their interviewing skills by responding to questions posed regarding a fictitious assistant principal position in a fictitious school. APs from the focus group mentioned the value of this activity in preparing them to secure their first AP position, touting it as one effective and practical aspect of their leadership preparation programming.

In both focus groups there was discussion of other particulars within the course of study that had significant relevance and practicality. Referring to exercises in a class focused on leadership for a diverse school population, one participant responded, "It opened my eyes to so many other different situations that kids go through, it's not just so much a black and white issue, it's a socioeconomic status, and it is urban versus rural, or suburban, even."

Another program element noted by respondents as beneficial and practical to their learning was a key action research project which provides formal training in the continuous improvement cycle but is implemented in the candidate's specific school. APs spoke positively regarding this very practical, real life assignment, as evidence by one comment, "And that action-based research was really good because it [school-based project] was able to kind of encompass some things that you don't realize is $[s i c]$ actually going on in your school, and you get to start doing different things and looking at different components." While one participant, quoted above, was concerned about the "financial animal," another participant noted,

My favorite project however, was still the budgeting project...where we actually had our fake school and we planned out a master calendar, a master schedule, and then also budgeted for the year. That was a really good awakening to see how much money a school gets and what you can actually do with it, and that was probably the most fun project I'd say we had to apply to our school.

The school law classes were also noted for their practicality and applicability as one participant stated, "You took the law stuff and were able to apply it back in situations...you think back, well, what did the [instructor] say about that?" Another participant shared, "There's a lot of practical stuff that you can't do beforehand like when you search somebody or you search a car." Another commented, "I think the real life applications from how to interrogate a student, how to know when I can search his phone and when I can't search his phone."

\subsubsection{Shock}

The third sub-theme under real life applications was described as the shock of school culture as noted by a participant,

When you have that first conversation with a kid, it's so different from being in the classroom. And it wasn't that I felt unprepared because it's just, I think I was unaware of how different the shock was going to be.

Participants emphasized the difference in "the way things are done," at various schools where they had taught or been an administrator. Adaptability seems an appropriate term in this context. A participant noted this change from his own personal experience, he stated, "And also culturally how those things change based on where you are. The school that I was at last year and the school that I'm at currently they're both urban schools but completely differently culturally." "Whether it's work at school or working sporting events, or whatnot, we're working 60-70 hours a week, and that's just how it is," a participant commented. Sharing personal experiences the participants spoke of cultural context and how schools were vastly different. These exchanges during the focus group meetings provided an opportunity for participants to apply concepts learned in the program and measure their effectiveness.

\subsubsection{The Importance of Guest Speakers}

The use of guest speakers in graduate-level educational leadership courses is a common practice. Guest speakers can provide valuable, real-world, auxiliary experiences which augment the course offering. This exposure to the real-world experiences of education practitioners promotes a healthy discussion and exchange of ideas according to participants of this study. The APs spoke of "current practicing assistant principals in either high school, middle, or elementary," who would "spend two hours [in class] talking about the last couple of days," and "events in their lives and that were eye-opening."

Reflecting deeply, a participant concluded, "But it was the war stories, it was the conversations they [guest speakers shared about which they] had with parents..." that were so meaningful to the APs during their pre-service leadership 
program because they provided a real life, practical perspective and understanding of the jobs they were soon to assume in their individual school settings.

\subsection{Mentoring}

The fourth theme that emerged as important from the focus group sessions with these AP was that of mentoring. For this study, we adopted the definition of mentoring articulated by Daresh (2004) as a professional relationship between an established professional and someone new to the field, with the mentor serving as, "someone willing to assume the challenge of assisting another in the formation of ideas and patterns of thinking" (p. 497). The theme, sub-themes, and some illustrative quotes are presented in Table 4.

Table 4. Mentoring Theme, Sub-themes, and Illustrative Quotes

Mentoring: "I told them, I said, look, I'm treating this like an internship...

so I'm going to ask you questions."

\begin{tabular}{ll}
\hline Support & "I had a great support group in the building already because I was in a school where there \\
& were three other assistant principals." \\
"The biggest thing is managing the relationships, both forming quality relationships and \\
then managing the ones that are in existence."
\end{tabular}

Mentoring fostered relationships that benefited both mentor and mentee, but this was not always the case.

\subsubsection{Support}

Focus group participants expressed an appreciation for those mentors present in their lives who had "been there and done that". Mentors who had been willing to share their experiences with these APs provided a rite of passage into school administration. It was not simply the good stories that these mentors shared, but also the "war stories" that participants wanted to hear. One participant shared, "It's the ability to learn from each, but also to realize that there are other people who were going through what you're going through that you're not the only one".

But, it was evident in the conversation that the support that each participant experienced with a mentor was different. "For me it was when I got into my role I had a great support group in the building already," stated one participant. But another shared about their mentors, "They were great people and great administrators, but they also weren't the most organized". Seizing the opportunity to frame the role she played as an AP, another participant stated, "And I told them [senior administrators/mentors], I said, look, I'm treating this like an internship, so I'm going to ask you questions".

The experiences and reflections that these APs shared indicated that the levels of support each received from his or her professional mentor varied substantially, some reporting positive experiences, some reporting a lack of help, and some reporting that the support they did receive was in response to them taking the initiative to seek out and garner that support from their senior administrators and from other colleagues in the building or district. In other words, support from a mentor was not automatic as they matriculated into this new role as a school leader.

\subsubsection{Relationships}

Yet, strong sentiment regarding developing and maintaining strong professional relationships, with their mentors, with their cohort classmates in their preparation program, and beyond, was commonly expressed and highly valued by the APs in our study. One participant noted, "The biggest thing is managing the relationships, both forming quality relationships and then managing the ones that are in existence". Participants in the study were cognizant of the fact that relationships were essential to their success as illustrated in this statement, "I just think continuing to focus on how to foster the right kind of relationships and maintain those relationships is really important because you can live or die on that sword if you don't do that well". Speaking about her cohort experience in the Educational Leadership program one participant noted,

The main thing is the relationships. I mean, when you spend this much time with someone, going through the cohort, not only do you learn from somebody else, but then you can build that relationship so that when [the program is] over, you have somebody that you can depend on, and lean on, to email, and ask a question, or get some advice. Sometimes it's good to get advice from outside your building because that advice might be a little skewed.

According to several participants, the cohort experience was a valuable part of their education. An AP shared, "the best part of class was after class when we were in the parking lot talking for 45 minutes about what was going on in 
our day and how we were dealing with other issues". The relationship-building after class was fueled by an interest in their peers' day-to-day challenges and in learning from one another about how they were handling various situations in their respective schools.

\section{Discussion}

As a reflective activity, faculty members from an Educational Leadership preparation program sought student perceptions regarding the effectiveness of their educational leadership preparation. Ensuring student needs are being met in an ever-changing educational environment is critical. The opportunity to gain insights into areas of perceived program strengths and weaknesses provides baseline data for program enhancement and future development.

In historical context, the AP role has been highly managerial in nature (Austin \& Brown, 1970). In a related article, our research team reported that participants in this study identified 27 different roles of the assistant principal (Gurley et al., 2015). These responsibilities have historically been, and continue to be, tasks that may be undesirable or mundane, but nonetheless seemingly represent a rite of passage to the principalship. Regarding their professional responsibilities, key aspects of their daily routine were discussed in great detail. Whether the AP role is truly a rite of passage or a perception in the minds of those en route, the perception is reality.

The central question of this research study was: "Did your educational leadership program prepare you for the roles as an assistant principal?" In response to this question the answer is a resounding yes-but. Yes, APs valued their formal graduate school education and felt prepared by the coursework and expertise of their professors and adjuncts. In the focus group discussions of principal preparation, many participants said they were as prepared as they could be for their leadership role. But, some participants stated that there are things that can only be learned after serving officially in the capacity of AP, a statement confirmatory of the adopted conceptual frameworks guiding this study (Browne-Ferrigno, 2003; Frese, 1982; Miller 2010, 2013; Shuval, 1980).

As the research team reflected upon the findings and themes emergent from these focus group discussions, and compared these findings to our conceptual frameworks of occupational socialization and role conceptualization (Browne-Ferrigno, 2003; Frese, 1982; Miller 2010, 2013; Shuval, 1980), we realized that, in addition to our best, formal efforts to prepare school leaders to assume key leadership roles in schools, critical amounts of professional learning indeed occurred for study participants after they were hired into formal school leadership positions.

While our team did not collect data regarding the pre-socialization processes experienced by respondents, before they found their way into a formal leadership preparation program, the data that we did collect confirmed that substantial amounts of occupational socialization and specific role conceptualization occurred for our respondents during the formal socialization stage (i.e., during their degree program participation), and especially during the post-formal or on-the-job stage of their development.

This conclusion was particularly substantiated when participants pointed out that there are simply some aspects of the job that can never be taught in a classroom, but can only be learned on-the-job and in the specific school setting to which they had been assigned. A key to understanding participant perspectives was recognizing the limitations of formal education. The apt description of their school environment being "real life", "school-specific", or the "shock" of learning a new school culture, revealed the anxiety participants experienced as they became immersed in the culture of their school and in their new roles as APs.

Schools are a microcosm of American society. The university program these respondents experienced was a precursor to the greater reality they would assume as school administrators. The APs were resolute in their leadership role, but many talked about the raw emotions of working with students and parents on a daily basis. Leadership exacted a heavy toll as many struggled to balance their work and home lives. They spoke of their inability to leave school concerns at the workplace. There was an unabashed and strong commitment to understanding and caring for all students. The participants appeared to researchers as proud professionals, dedicated to their students and the communities they serve and represent.

AP use of the term "real life" differentiated their formal education from the oftentimes harsh reality of their work environments. A participant referred to it as making real life application of the knowledge they had acquired. It was the ability to apply formal learning to a constantly evolving and at times, hostile culture. This was the preparation that was discussed as being beyond the classroom and explains many participant comments. APs spoke of incidents at their schools in which they recalled a professor's classroom comments, but they had to adapt and apply this knowledge in real time. The challenge was no longer a case study, or an academic exercise, but rather a real life decision with far reaching consequences. The connotation confirms a long-believed reality that students can read about leadership in a textbook, but in real life, the practice of leadership can be very different. 
Respondents identified real life experiences as different from school-specific preparation as the latter dealt exclusively with preparation that cannot take place until the AP learns the school district policies, student code of conduct, and many other issues related to their specific workplace setting. Again, this preparation cannot occur until APs are in their actual place of employment and performing their specific assigned duties. A few participants felt prepared upon their graduation from the program, citing the only thing that they were not prepared for were the school specific policies and procedures which they had yet to learn.

A third category in the focus group preparedness discussion was the shock of culture. In an emotional time of sharing, participants spoke of deplorable situations in which their students live. Respondents spoke of the challenge of watching their students painstakingly trying to navigate some very undesirable life conditions and circumstances. The APs spoke of the emotional toll this had on their personal lives. APs referred to the emotional weight of the sad things that happen to kids, resulting in the APs being forced to seek out ways to protect themselves emotionally and then to find ways to help the kids, emotionally. Dealing with this type of emotional shock was notably mentioned as an area in which some APs did not feel prepared by their university leadership program.

Researchers suggested the graduate program in educational leadership should continue to examine and assess the ever-expanding influence of culture and its impact on school leadership preparation. While real life, school-specific, and shock of culture are areas of unpreparedness cited by some participants, the focus groups highly esteemed their formal training. Many participants mentioned individual professors whose words, guidance, and counsel had prepared them for the rigors of school administration. Furthermore, they collectively recalled experiences in the classroom and with each other that had had a profound influence in their professional lives. After class sessions, cohorts often lingered in the parking lot to discuss problems in their schools, and to ask about specific policy and procedure issues. The cohorts extended knowledge through their collegiality, networking, and collaborative skills.

The gaps in the AP expertise were largely the result of time management issues as young administrators transitioned from a teaching to administrative role. Participants graduated from their leadership programs with knowledge of technology and best practices, but those skills were difficult to retain as APs become immersed in administrative responsibilities. The responses coded as "gaps" related to specific and sometimes highly technical program features.

APs are increasingly referred to as instructional leaders which demands an ever-expanding knowledge base grounded in both theory and practice. Based upon the data gathered from these respondents, the research team proposes that the problem of developing as an instructional leader is at least two-fold. First, many responsibilities assigned to APs are menial tasks that, from their perspective, do not provide the skills necessary to become an effective instructional leader.

Second, time management is a daunting challenge for APs, as noted by a participant who stated she was losing her technology skills from being out of the classroom and absorbed in administrative responsibilities. Instructional leaders must lead from the front with regard to technology and therefore identifying this gap and addressing the matter is critical. New and unanticipated challenges were identified such as athletic management and oversight. Perhaps due to the unique athletic culture that permeates many schools, the sheer scope of responsibility and accountability to oversee the interplay of many different agencies related to athletic program management is a cause of great concern. This new role is indicative of the all-encompassing tasks of the AP.

\subsection{Implications for Program Improvement}

It is imperative that university educational leadership programs, such as the one under review in this study, be in a perpetual cycle of self-assessment to insure program relevance and to insure that program graduates are as prepared as possible to assume school leadership roles, particularly as APs. Findings from this admittedly small, yet powerful, data set provide evidence for the research team of the ever-increasing scope and complexity of the roles APs must assume and suggest several implications to the research team regarding improvement for the school leadership program under review.

First, leadership faculty and program planners would be well-advised to prepare candidates for the inevitability of learning gaps they will experience upon matriculation to formal leadership roles in schools. Leadership faculty will serve their students well by openly addressing the fact that all of the learning they will need to acquire to become effective school leaders can never be fully addressed in the classroom. Rather, many significant learning needs will present themselves, on a continual basis, as school leaders enact leadership roles and make decisions in the best interest of their students and schools. Therefore, the necessity of preparing leadership students to expect such learning gaps, and facilitating ways which they can address, and fill in, these learning gaps on their own, seems to be indicated by study findings. Encouraging leadership candidates to develop and maintain strong mentoring 
relationships within and beyond their school settings will undoubtedly prove to be a promising strategy to address such learning gaps as they emerge.

For example, the loss of technological expertise as APs transitioned from teachers to first-year assistant principals was noted. Conscientious teachers diligently do their duty to learn and apply emerging technologies that advance course content. However, that pursuit was often sacrificed as participants transitioned into administrative ranks. While APs cited their graduate program as effectively preparing them in emerging technologies the perceived gap occurred after graduation. As a first-year administrator adjusting to the multifaceted roles and responsibilities inherent with the position, APs often lost the technological expertise acquired as classroom teachers. The time required to learn and apply technology initiatives in their specific school environment was simply not available. Therefore, APs indicated that their skills had regressed as time management became an issue.

As faculty, we believe that participants should have the same commitment to emerging technologies they previously held as classroom teachers, so as to facilitate and model the behavior required for instructional leaders in $21^{\text {st }}$ century schools; therefore, the development of a stronger self-education mentality that fuels a broader learning culture while advancing to administrative positions is needed. Realizing that continuous improvement is a precursor to professional development, self-education sessions are critical. UAB has a partnership with many school districts and perhaps the evolving responsibilities of leadership can be evaluated pursuant to the significant contribution emerging technologies can make within school leadership.

Second, leadership programming may be improved substantially by helping to prepare pre-service school leaders for the emotional challenges of the job. As school leaders rise through the ranks of the organizational leadership structure in their schools, they will inevitably become increasingly exposed to the harsh and often emotionally charged realities of their students' lives. Rather than allowing these emerging professionals to become overly burdened by these realities, school leadership programs would be well-advised to proactively prepare students to cope with such demands. Working with students to build an increased familiarity with, and develop effective strategies to address, the broad scope of emotional challenges they will face in their new roles appears to be a reasonable response and goal for leadership program planning.

One such strategy is to incorporate a support system for administrators-in-training. Developing a better understanding of the workplace environment and the stressful nature of daily interactions is a first step. Sharing coping strategies among adjunct faculty and practitioners who teach in our program, make decisions in real time, and are frequently dealing with personal emotions and the plight of students in their schools may be an important arrangement in which APs can be supported. Adapting coursework to facilitate a flow of information that helps identify effective coping practices and social supports may also provide benefits to APs. Receiving information to more effectively manage their work environment can be a by-product of this arrangement.

Again, helping pre-service leaders to establish mentoring relationships, and develop a strong network of people who can support these emergent leaders emotionally, is indicated. Further, helping leadership candidates develop a strong knowledge base of area social service providers (i.e., knowing whom to call and when) could also help to ameliorate the challenges they will face in effectively supporting their students.

Finally, our study provides further evidence for the necessity of helping students make connections between the more theoretical or book learning they experience in their leadership classrooms to the practical application of this knowledge in the context of their roles in schools. Continued emphasis on the practical application of coursework to real life demands that will be presented in the school leadership role is of paramount importance. Our team of educational leadership faculty members is renewed in our commitment to strengthen this connection, and to invite and include the input of practitioners in course planning and preparation, seeking the advice and guidance of current school leaders in our effort to increase the relevance of course assignments and activities to prepare our students to assume the challenging roles they face as emerging school leaders.

The panel of experts used by our educational leadership program consists of practitioners from whom the program obtains expertise and support within a particular course, either by consultation or in class sessions to which the practitioners were invited. In discussing their responsibilities, panel members acted as mentors serving the educational leadership program and in that capacity received instructions from the course professor. In the future, program faculty should endeavor to have panels with the broadest representation in terms of knowledge, diversity, and professional experience in school administration. Increasingly, this panel of experts should act as a sounding board, enabling students to benefit from their experience and invaluable perspectives on school policy issues.

The panels can and do provide insights and guidance on subjects that are current in school systems and challenging 
for new APs. Professors should continue to form multiple-district panels which provide a rich context for comparisons and overall discussions. These panels have been well-received by students and their role can be accentuated by focusing on critical issues such as the "shock of school culture" and "real life" scenarios identified by participants in this study. As experienced school administrators, panelist knowledge of professional practice and personal expertise, along with their purposeful storytelling skills provide a highly practical and adaptable learning environment from which students learn and grow professionally. The collaborative effort of involving practitioners, students, and faculty meshes theory with practice, resulting in a highly practical, interactive, and continuing dialogue.

\subsection{Conclusion}

Preparing school leaders who are competent and well-equipped to lead schools in a multitude of ways is the ultimate goal for this educational leadership program and for others around the country. Attending to the voices of recent graduates who have recently assumed key leadership roles in their schools is imperative. As a result of reflecting on the findings of this study where we have done precisely that, our research team has been renewed in its commitment to strengthening current, promising practices, and developing new approaches and strategies that will help our students more effectively assume these critical roles.

\section{References}

Armstrong, D. E. (2004). Personal change and organizational passages: Transitions from teacher to the vice principalship in a reform climate (Unpublished doctoral dissertation). Retrieved from OISE/University of Toronto, Ontario, Canada.

Armstrong, D. E. (2009). Administrative passages: Navigating the transition from teacher to assistant principal. New York: Springer.

Austin, B. D., \& Brown, H. L. (1970). Report of the assistant principalship, Volume 3: The study of secondary school principals. Washington, DC: National Association of Secondary School Principals.

Backor, K. T., \& Gordon, S. P. (2015). Preparing principals as instructional leaders: Perceptions of university faculty, expert principals, and expert teacher leaders. NASSP Bulletin, 99(2), 105-126. http://dx.doi.org/10.1177/0192636515587353

Barnett, B. G., Shoho, A. R., \& Oleszewski, A. M. (2012). The job realities of beginning and experienced assistant principals. Leadership and Policy in Schools, 11(1), 92-128. http://dx.doi.org/10.1080/15700763.2011.611924

Blase, J., \& Blase, J. J. (2006). Teachers bringing out the best in teachers: A guide to peer consultation for administrators and teachers. Thousand Oaks, CA: Corwin Press.

Bolman, L. G., \& Deal, T. E. (1997). Reframing organizations: Artistry, choice, and leadership (2 ${ }^{\text {nd }}$ ed.). San Francisco: Jossey-Bass.

Boske, C., \& Benavente-McEnery, L. (2012). The quiet roar: Assistant principals leading for social justice. In A. R. Shoho, B. G. Barnett, \& A. K. Tooms (Eds.), Examining the assistant principalship: New puzzles and perennial challenges for the $21^{\text {st }}$ century (pp. 125-152). Charlotte, NC: Information Age Publishing.

Browne-Ferrigno, T. (2003). Becoming a principal: Role conception, initial socialization, role-identity transformation, purposeful engagement. Educational Administration Quarterly, 39(4), 468-503. http://dx.doi.org/10.1177/0013161X03255561

Busch, S. D., MacNeil, A. J., \& Baraniuk, M. S. (2012). In A. R. Shoho, B. G. Barnett, \& A. K. Tooms (Eds.), Examining the assistant principalship: New puzzles and perennial challenges for the $21^{\text {st }}$ century (pp. 35-58). Charlotte, NC: Information Age Publishing.

Cosner, S., Tozer, S., \& Smylie, M. (2012). The ED.D. program at the University of Illinois at Chicago: Using continuous improvement to promote school leadership preparation. Planning \& Changing, 43(1/2), 127-148.

Creswell, J. W. (2003). Research design: Quantitative, qualitative, and mixed methods approaches (2 ${ }^{\text {nd }}$ ed.). Thousand Oaks, CA: Sage.

Creswell, J. W. (2007). Qualitative inquiry \& research design: Choosing among five approaches. Thousand Oaks, CA: Sage.

Daresh, J. (2004). Mentoring school leaders: Professional promise or predictable problems? Educational Administration Quarterly, 40(4), 495-517. http://dx.doi.org/10.1177/0013161X04267114

Donmoyer, R., Imber, J., \& Scheurich, J. (1995). The knowledge base in educational administration: Multiple perspectives. Albany: State University of New York Press. 
Foster, L., \& Ward, K. (1998). The internship experience in the preparation of higher education administrators: A programmatic perspective. The AASA Professor, 222(2), 14-18.

Frese, M. (1982). Occupational socialization and psychological development: An underemphasized research perspective in industrial psychology. Journal of Occupational Psychology, 55, 209-224. http://dx.doi.org/10.1111/j.2044-8325.1982.tb00095.x

Fullan, M. (2003). Change forces with a vengeance. New York: Routledge \& Falmer Press. http://dx.doi.org/10.4324/9780203165805

Fulton, O. K. (1987). Basic competencies of the assistant principal. NASSP Bulletin, 71, 52-54. http://dx.doi.org/10.1177/019263658707150115

Glanz, J. (1994). Dilemmas of assistant principals in their supervisory role: Reflections of an assistant principal. Journal of School Leadership, 4(5), 577-590.

Glaser, B. G. (1978). Theoretical sensitivity: Advances in the methodology of grounded theory. Mill Valley, CA: Sociology Press.

Glaser, B. G. (1992). Basics of grounded theory analysis: Emergence vs. forcing. Mill Valley, CA: Sociology Press.

Gordon, M. (1998). A dictionary of sociology. Retrieved from: http://www.encyclopedia.com/doc/1088-occupationalsocialization.html.

Greenfield, W. (1985). Developing an instructional role for the assistant principal. Education and Urban Society, 18, 85-92. http://dx.doi.org/10.1177/0013124585018001005

Gurley, D. K., Peters, G. B., Fifolt, M., Collins, L., \& McNeese, R. (2015). Addressing the multiplicity of roles of the assistant principal: Insights from the field. Journal of Behavioral and Social Sciences, 3, 135-147.

Hallinger, P., \& Heck, R. H. (1998). Exploring the principal's contribution to school effectiveness: 1980-1995. School Effectiveness and School Improvement, 9(2), 157-191. http://dx.doi.org/10.1080/0924345980090203

Halverson, T. J., \& Plecki, M. L. (2015). Exploring the politics of differential resource allocation: Implications for policy design and leadership practice. Leadership and Policy in Schools, 14(1), 42-66. http://dx.doi.org/10.1080/15700763.2014.983129

Hartzell, G. N. (1993). The assistant principal: Neglected actor in practitioner leadership literature. Journal of School Leadership, 3(6), 707-723.

Hartzell, G. N., Williams, R. C., \& Nelson, K. T. (1995). New voices in the field: The work lives of first-year assistant principals. Thousand Oaks, CA: Corwin Press.

Harvey, M. J. (1994). The deputy principalship: Retrospect and prospect. The International Journal of Educational Management, 8, 15-25. http://dx.doi.org/10.1108/09513549410062407

Hennink, M. M. (2007). International focus group research: A handbook for the health and social sciences. Cambridge, MA: Cambridge University Press. http://dx.doi.org/10.1017/CBO9780511619458

Hess, F., \& Kelly, A. (2005). An innovative look, a recalcitrant reality: The politics of principal preparation reform. Educational Policy, 19(1), 155-180. http://dx.doi.org/10.1177/0895904804270776

Isreal, M. S., \& Fine, J. (2012). Moving outside the comfort zone: An innovative approach to principal preparation. Planning \& Changing, 43(3/4), 294-308.

Kotter, J. P. (1985). Power and influence: Beyond formal authority. New York: Free Press.

Kwan, P. \& Walker, A. (2012). Assistant principals in Hong Kong: Their responsibility, role assignments, and job satisfaction. In A. R. Shoho, B. G. Barnett, \& A. K. Tooms (Eds.), Examining the assistant principalship: New puzzles and perennial challenges for the $21^{\text {st }}$ century (pp. 59-80). Charlotte, NC: Information Age Publishing.

Lashway, L. (2003). Leaders for America's schools. Retrieved from https:// scholarsbank.uoregon.edu/xmlui/bitstream/handle/1794/3255/leaders_book.pdf?sequence=1

Leithwood, K., \& Duke, D. L. (1999). A century's quest to understand school leadership. Handbook of research on educational administration. San Francisco: Jossey-Bass.

Lehman, L. (2013). Principal internships in Indiana: A promising or perilous experience? NCPEA International Journal of Educational Leadership Preparation, 8(1), 1-19.

Levine, A. (2005). Educating school leaders. The Education Schools Project: Washington D.C. Retrieved from: http://files.eric.ed. gov/fulltext/ED504142.pdf

Lincoln, Y. S., \& Guba, E. G. (1985). Naturalistic inquiry. Thousand Oaks, CA: Sage. 
Marshall, C. (1992). Assistant principalship: An overview of the frustrations and rewards. NASSP Bulletin, 76, 88-94. http://dx.doi.org/10.1177/019263659207654711

Marshall, C., \& Greenfield, W. (1987). The dynamics in the enculturation and the work in the assistant principalship. Urban Education, 22, 36-52. http://dx.doi.org/10.1177/004208598702200103

Marshall, C., \& Hooley, R. M. (2006). The assistant principal: Leadership choices and challenges. Thousand Oaks, CA: Corwin Press.

Marshall, C., \& Mitchell, B. (1991). The assumptive worlds of fledgling administrators. Education and Urban Society, 23(4), 396-415. http://dx.doi.org/10.1177/0013124591023004004

Martinez, J. (2011). Assistant principal frustrations, obstacles, and recommended changes (Doctoral dissertation). Retrieved from ProQuest Dissertations Publishing (3462931).

McCracken, G. (1988). The long interview. Ontario: Sage. http://dx.doi.org/10.4135/9781412986229

Melton, T. D., Mallory, B. J., Mays, R., \& Chance, L. (2012). Challenges to school leadership practice: Examining the assistant principalship (deputy headship) in the United States, UK, and China. In A. R. Shoho, B. G. Barnett, \& A. K. Tooms (Eds.), Examining the assistant principalship: New puzzles and perennial challenges for the $21^{\text {st }}$ century (pp. 81-110). Charlotte, NC: Information Age Publishing.

Merriam S. B., \& Associates (2002). Qualitative research in practice: Examples for discussion and analysis. San Francisco: Jossey-Bass.

Miller, S. E. (2010). A conceptual framework for the professional socialization of social workers. Journal of Human Behavior in the Social Environment, 20(7), 924-938. http://dx.doi.org/10.1080/10911351003751934

Miller, S. E. (2013). Professional socialization: A bridge between the explicit and implicit curricula. Journal of Social Work Education, 49, 368-386.

Miskel, C., \& Cosgrove, D. (1985). Leader succession in school settings. Review of Educational Research, 55, 87-105. http://dx.doi.org/10.3102/00346543055001087

Orr, M. T., \& Pounder, D. (2006). UCEA/TEA-SIG Taskforce on evaluating leadership preparation programs. Taskforce Report: Six Years Later. Paper presented at the Annual Conference of the University Council for Educational Administration, San Antonio, Texas.

Patton, M. Q. (1990). Qualitative evaluation and research methods ( $2^{\text {nd }}$ ed.). Newbury Park, CA: Sage.

Pellicer, L. O., Anderson, L. W., Keefe, J. W., Kelly, E. A., \& McCleary. L. E. (1988). High school leaders and their schools, Vol. I: A national profile. Reston, VA: National Association of Secondary School Principals.

Read, S. P. (2012). Factors that influence the preparedness of teachers for the vice-principal role. In A. R. Shoho, B. G. Barnett, \& A. K. Tooms (Eds.), Examining the assistant principalship: New puzzles and perennial challenges for the $21^{\text {st }}$ century (pp. 11-34). Charlotte, NC: Information Age Publishing.

Rintoul, H. (2012). The new urgency of vice-principalship: Ethical decision making. In A. R. Shoho, B. G. Barnett, \& A. K. Tooms (Eds.), Examining the assistant principalship: New puzzles and perennial challenges for the $21^{\text {st }}$ century (pp. 111-124). Charlotte, NC: Information Age Publishing.

Sergiovanni, T. J. (2001). The principalship: A reflective practice perspective. Boston: Allyn and Bacon.

Shoho, A. R., Barnett, B. G., \& Tooms, A. K. (2012). Examining the assistant principalship: New puzzles and perennial challenges for the $21^{\text {st }}$ century. Charlotte, NC: Information Age Publishing.

Shuval, J. T. (1980). Entering medicine: The dynamics of transition. A seven-year study of medical education in Israel. Oxford, UK: Pergamon Press.

Stoll, L. (1998). School culture. School Improvement Bulletin, 9(3), 9-14.

Webb, R., \& Vulliamy, G. (1995). The changing role of the primary school deputy headteacher. School Organisation, 15, 53-64. http://dx.doi.org/10.1080/0260136950150107

Wilmore, E. L. (2002). Principal induction: A standards-based model for administrator development. Thousand Oaks, CA: Corwin Press.

Yirci, R., \& Kocabas, I. (2010). The importance of mentoring for school principals: A conceptual analysis. Education Leadership Review, 11(1), 1-7.

Young, M. D., Mountford, M., \& Crow, G. M. (2005). Preparing educational leaders: A roadmap to success. Educational Considerations, 32(2), 3-5. 